\title{
Ensino na Comunidade e Inteligência Coletiva: Partilhando Saberes com o WIKI'
}

\section{Teaching in the Community and Collective Intelligence: Sharing Knowledge with WIKI}

\author{
Antonio Pithon Cyrino \\ Viviany Menossi do Amaral \\ Ana Cláudia Cavalcante Espósito ${ }^{\mathrm{I}}$ \\ Vera Lúcia Garcia \\ Eliana Goldfarb Cyrino ${ }^{I}$ \\ Denise de Cássia Moreira Zornoff ${ }^{I}$
}

\author{
PALAVRAS-CHAVE: \\ - Ensino na Comunidade \\ - Inteligência Coletiva \\ - Tecnologias de Comunicação \\ e Educação
}

\section{KEYWORDS:}

- Community-Based Teaching

- Collective Intelligence

- Communication and Education Technology

Recebido em: 31/03/2010

Reencaminhado em:13/09/2010

Aprovado em: 18/09/2010

REVISTA BRASILEIRA DE EDUCAÇ̃̃o MÉDICA $6 4 \longdiv { 3 6 ( 1 , \text { Supl. 1): } 6 4 7 0 ; 2 0 1 2 }$
*Este trabalho é uma versão ampliada daquela apresentada no "VI Congreso de Internacional Docencia Universitaria e Inovación", Barcelona, 2010. I Universidade Estadual Paulista "Júlio de Mesquita Filho", Botucatu, SP, Brasil. 


\section{INTRODUÇÃO}

Este estudo de intervenção e pesquisa apresenta o programa de ensino na comunidade - Interação Universidade-Serviço-Comunidade (Iusc) - desenvolvido há sete anos na Faculdade de Medicina de Botucatu-Unesp (FMB-Unesp), o qual envolve disciplinas oferecidas nos três primeiros anos da graduação em Medicina e que pode ser reconhecido como uma inovação pedagógica.

A FMB-Unesp foi uma das instituições selecionadas pelos Ministérios da Saúde e da Educação para participar do Programa de Incentivo às Mudanças Curriculares nos Cursos de Medicina (Promed) e do Programa Nacional de Reorientação da Formação Profissional em Saúde (Pró-Saúde). Para tanto, essa instituição de ensino apresentou um projeto ensejando reformulações pedagógicas e curriculares, dentre as quais, propôs ampliar a vivência dos graduandos junto à comunidade, mediante o programa de Interação Universidade-Serviço-Comunidade (Iusc).

Em 2003, a FMB-Unesp implantou o Iusc envolvendo, gradativamente, alunos do primeiro ao terceiro ano do curso de Medicina. Desde 2008, a disciplina passou a envolver também docentes e alunos curso de Enfermagem dessa mesma instituição. São objetivos do programa: promover a integração entre estudantes, docentes, serviços e comunidade; proporcionar ao aluno a compreensão das condições de vida da comunidade;aprimoraras habilidades de comunicação do graduando; valorizar a integração dos conhecimentos clínicos com a assistência individual; e sensibilizar para o desenvolvimento de um cuidado integral e humanizado na prática da atenção primária à saúde ${ }^{1,2}$.

Em pequenos grupos e sob supervisão de um professor tutor, os alunos atuam durante os três anos em uma mesma região do município de Botucatu, no estado de São Paulo, correspondente à área de abrangência de uma unidade de saúde. Assim, nos dois primeiros anos, ficam responsáveis pelo acompanhamento de famílias com crianças menores de 1 ano de idade, sob supervisão do tutor. Nessas visitas domiciliares, os graduandos observam a realidade da comunidade e, mediante a problematização desse universo, são estimulados a compreender as relações entre condições de vida e saúde. A partir da apreensão dessa realidade, no segundo ano, os alunos são instigados a ampliar o conhecimento a respeito da área em que atuam, de modo a desenvolver projetos de intervenção articulados aos problemas percebidos. Já no terceiro ano, a expectativa é que os alunos possam realizar uma atenção clínica ampliada na atenção básica, reconhecendo as singularidades daquela comunidade em sua prática de atenção.
O programa toma como perspectiva o conceito de que a vivência em sociedade é essencial para a transformação do homem de ser biológico em ser humano ${ }^{3}$,pois é pela aprendizagem nas relações com os outros que se constrói os conhecimentos que permitem o desenvolvimento mental do indivíduo. Dessa forma, o Iusc buscou, nesses sete anos de existência, integrar o aluno à comunidade, promovendo um ambiente de troca, interação, cooperação e produção compartilhada de conhecimentos.

Tal orientação aproxima o programa do transdisciplinar campo da inteligência coletiva devido ao fato de estar centrado no estudo das possibilidades de exploração da "potência de ação coletiva" dos grupos, entendendo que essa "potência depende fundamentalmente da capacidade de indivíduos e grupos interagirem, pondo-se em relação e, dessa forma, produzirem, trocarem e utilizarem conhecimentos" ${ }^{\prime 4}$ (p. 220).

Para Lévy, a inteligência coletiva é o projeto de uma inteligência variada, distribuída em toda parte, sempre valorizada e posta em sinergia em tempo real, sendo uma nova forma de laço social no qual cada ser humano é, para os outros, uma fonte de conhecimentos. A inteligência coletiva não é a fusão das inteligências individuais em uma espécie de "magma comunitário", mas, ao contrário, é a valorização e a reativação mútua das singularidades ${ }^{5}$.

As comunidades de práticas, que alcançaram um grande crescimento com as novas tecnologias de informação e comunicação (TICs), especialmente a Internet,são um exemplo de possibilidades de produção, troca e cooperação em coletivos. Ao mesmo tempo, expressam bem o valor que o conhecimento vem assumindo na sociedade contemporânea, inclusive aquele não oficial e que se estrutura fora dos sistemas tradicionais de certificação ${ }^{6}$

Pierre Lévy reconheceu que a constituição de "coletivos inteligentes" podem "reinventar o laço social em torno do aprendizado recíproco, da sinergia, das competências, da imaginação e da inteligência coletiva"7 (p.26), com potência para a expressão de alteridades. Trata-se essencialmente de um espaço de transformação das relações, de aparecimento de outra qualidade de ser em um processo de articulação das subjetivações individuais e coletivas. Essa perspectiva poderá ser aberta se se entende que, em nossa "sociedade do conhecimento", é impossível que um indivíduo sozinho domine todo o saber e disponha de todas as competências, o que aponta e reforça a necessidade de cooperação e compartilhamento de conhecimentos entre as pessoas e valoriza o saber de cada um $^{8}$.

As tecnologias da inteligência, em especial a oralidade, a linguagem escrita e o meio eletrônico em rede, são consideradas, simultaneamente, suporte e parte integrante dos proces- 
sos cognitivos ${ }^{7}$. Como tal, a inteligência coletiva condiciona, sem determinar, as formas de pensar e nutrem de formas específicas os processos de conhecer, "pois é ao redor dos equipamentos coletivos da percepção, do pensamento e da comunicação que se organiza em grande parte a vida da cidade no cotidiano e que se agenciam as subjetividades dos grupos" (p. 186-187).

Tendo em vista que a interatividade é essencial à produção de uma inteligência coletiva, o uso de comunidades virtuais e/ou de tecnologias que permitam a produção coletiva, como a ferramenta Wiki, são bastante úteis para construir e disseminar os saberes.

Produzir uma inteligência coletiva é acreditar que seja possível a criação de um "espaço do saber", o qual só pode "assumir sua plena significação quando houver um exercício próprio que 'ponha em comum' os saberes e as competências de uma comunidade" (p.3). A construção desse "espaço do saber implica em disponibilizar toda forma de conhecimento para cada um e para todos simultaneamente" e, assim, produzir uma nova forma de laço social ${ }^{9}$ (p.3).

Neste trabalho, a ideia é se apropriar de novas tecnologias de informação e comunicação (TICs) como recurso para promover uma maior aproximação entre alunos, docentes, profissionais de saúde e comunidade, de modo a articular o processo de ensino-aprendizagem à vivência do cotidiano de uma dada comunidade. Comisso, espera-se desencadear um processo reflexivo nos alunos, de forma a integrar conhecimento prático e teórico, bem como aproximá-los da realidade da comunidade em que estariam inseridos, pela oportunidade de construir sua própria experiência.

Trabalhar na/com a comunidade exige, ainda, reconhecer os limites do uso do próprio termo-comunidade-por ensejar um sentido de homogeneidade e unidade que não é próprio da realidade dos bairros de periferia de nossas cidades. Desse modo, a equipe do Iusc tem buscado operacionalizar a aplicação do conceito de território desenvolvido pelo geógrafo Milton Santos, para reconhecer toda a riqueza do quese denomina "periferia".

Nesse sentido, tem-se procurado ampliar o olhar sobre esse "lugar" observando-se suas vertentes política, cultural, econômica e naturalista ${ }^{10}$, identificando o território como um espaço articulado, conectado e integrado, no qual as relações sociais são continuamente construídas, o que lhe dá movimento, fluidez e interconexão.

É a partir dessa visão integradora que se tem estudado cada território do município de Botucatu, SP, enquanto campo de atividades do Iusc, mediante a atuação conjunta de alunos de graduação médica (do $1^{\circ}$ ano), professores, profissionais de saúde e membros da comunidade.
Neste estudo, buscou-se a construção de um "espaço coletivo do saber" em um território do município de Botucatu -região do Jardim Cristina-a partir da criação de uma página Wiki, cujo conteúdo foi produzido pelos alunos de graduação e com o envolvimento de membros da comunidade, buscando valorizar esta em sua riqueza histórica, cultural e social. Assim, procurou-se ampliar o envolvimento simultâneo e integrado dos diferentes partícipes do Iuscpor meiodo uso exploratório de tecnologias de informação e comunicação, a saber: osoftware Wiki, com especial destaque para a coprodução de conhecimento envolvendo Universidade e comunidade.

Desse modo, foram objetivos deste estudo: construir e implementar um espaço de comunicação entre estudantes de Medicina e Enfermagem e membros da comunidade visando a estimular a formação de uma inteligência coletiva sobre determinado território e experimentar a utilização do software Wiki como ferramenta de produção coletiva de saberes sobre esse mesmo espaço.

\section{METODOLOGIA}

Trata-se de uma pesquisa-ação de natureza exploratória desenvolvida a partir da parceria entre o Programa (Disciplina) de Interação Universidade-Serviço-Comunidade- Iusc I, II, III, o Departamento de Saúde Pública e o Núcleo de Educação a Distância e Tecnologia de Informação em Saúde (NEAD.TIS) da Faculdade de Medicina de Botucatu- Unesp.

Dado o envolvimento dos pesquisadores no Programa Iusc, tanto professores quanto alunos, pode-se caracterizar este estudo como uma pesquisa qualitativa do tipo pesquisa-ação. Na pesquisa-ação, os pesquisadores pretendem desempenhar um papel ativo na realidade a ser pesquisada, na qual se envolvem como atores ${ }^{11}$. Tal papel não será necessariamente a resolução dos problemas, mas o esclarecimentodestes para os grupos e pessoas envolvidas. Assim, o principal objetivo da pesquisa-ação não é apenas seu entrosamento com a ação em si, mas a possibilidade de torná-la acessível aos cidadãos. Além desses objetivos práticos, a pesquisa-ação, como outras metodologias de pesquisa, buscaproduzir conhecimento ${ }^{11}$.

Em 2007 e 2008, foi realizado treinamento com a plataforma Moodle e com a ferramenta Wiki pelo Núcleo de Educação a Distância e Tecnologias de Informação em Saúde (NEAD. TIS) para parte dos docentes e todos os alunos do Iusc I

O projeto foi desenvolvido em três etapas articuladas: 1) reconhecimento do território; 2) desenvolvimento de página Wiki enquanto espaço de registro e produção coletiva de conhecimento sobre o território; e 3) descrição e análise do processo desenvolvido. 
O campo deste estudo compreendeu a disciplina Iusc I, desenvolvida de modo integrado com alunos da graduação de Medicina ede Enfermagem, e a área de abrangência da Unidade Básica de Saúde do Jardim Cristina, na cidade de Botucatu, estado de São Paulo.

Participaram das etapas 1 e 2 desta pesquisa dois grupos do Iusc Icomposto por 12 alunos da graduação de Medicina e Enfermagem cada um, totalizando 24 alunos nos dois anos de atividade em 2007 e 2008.

A primeira etapa - reconhecimento do território- foi realizada por um dos grupos mediante orientação de professor tutor partícipe desta investigação. O reconhecimento do território consta da observação direta com o objetivo de caracterizar o lugar, e foi realizado pelo uso de diferentes mídias (fotografia, áudio e vídeo), de modo a captar o espaço em suas especificidades históricas, políticas, culturais e econômicas. Algumas lideranças foram entrevistadas pelos alunos, que tiveram inserção no Moodle, plataforma de ensino a distância, que foi utilizada experimentalmente no curso. A entrevista semiestruturada mostrou-se um instrumento bastante adequado para a obtenção de informações acerca do que as pessoas creem, esperam, desejam, bem como acerca de seus saberes sobre diferentes questões. Dessa forma, os entrevistados puderam contribuir com sua memória e saberes sobre o território estudado.

Na segunda etapa, desenvolveu-se a página Wiki especificamente para o projeto, denominada WikiIUSC. Neste sítio se pretendeu explorar as possibilidades de produção coletiva de conhecimento orientadas em torno do reconhecimento do referido território, buscando-se explorar sua riqueza e complexidade.

O software Wiki,escolhido para o desenvolvimento desta pesquisa, privilegia os aspectos mais importantes das recentes tecnologias, especialmente para a educação, dado seu caráter colaborativo, que permite sua aplicação em ambientes pedagógicos informatizados ${ }^{12}$. O Wiki permite a produção de textos coletivos, a discussão a respeito dessa produção textual e ainda registra todas as alterações processadas na página. Desse modo, uma das grandes vantagens no uso do Wikié a expansão de um texto plural ${ }^{13}$.

Como o Wiki é um instrumental propício à interatividade e a conexões em hiperlink, possibilitando a escrita de hipertextos coletivos e colaborativos ${ }^{12}$, esse tipo de atuação torna o processo de aprendizagem mais amplo, pois há troca de informações que são articuladas, contextualizadas e debatidas, favorecendo a construção coletiva do conhecimento.

A principal característica do Wiki éa autoria coletiva, que o torna útil para projetos em que se busca o papel de protago- nismo e construção coletiva em uma comunidade, como é o objetivo deste estudo.

O softwareWiki é um gerenciador de conteúdos queopera como um sítio (website) e representa um novo passo na evolução da Internet (web 2.0), ao permitir que seus usuários possam ser, ao mesmo tempo, autores, editores e leitores. Isso pode se dar com vantagens, pois o Wiki permite combinar a flexibilidade da interação humana com a independência no tempo e no espaço.

Para a aplicação explorada neste caso, espera-se o progressivo envolvimento dos alunos da graduação, dos docentes, dos profissionais da saúde e dos membros da comunidade. Ao mesmo tempo, pretende-se que o uso do Wikifaça com que o registro dos estudos do território, realizados anualmente pelos alunos, torne-se disponível para todos, principalmente para a comunidade que vive no território estudado.

Todavia, a aposta desta equipe de pesquisadores é a de que a comunidade possa se apropriar do espaço construído com a tecnologia Wiki não só como leitora da história produzida pelos alunos e professores, mas, sobretudo, comoredatora de outra versão, transformando-o em um verdadeiro espaço de construção coletiva de conhecimento sobre o território.

Em caráter experimental, o envolvimento da comunidade foi articulado por meio de parceria com o Projeto Crescer, localizada na área de abrangência do estudo. A proposta viabilizou-se com a participação de grupo de jovens que lá recebem aulas de Informática. Tal iniciativa foi bem-aceita pela direção da instituição, pois proporcionou a possibilidade dos alunos ampliarem seus conhecimentos na área de Informática e na elaboração de textos coletivos, principalmente pela valorização da história e cultura da comunidade.

Assim, participaram também do estudo um grupo de jovens da comunidade formado por 25 adolescentes entre 12 a 15 anos, inscritos no curso regular de Informática, que configura um projeto social voltado para esse público e oferecido pela instituição.

Para o uso da ferramenta Wiki, foi realizado treinamento com os alunos da graduação, os pesquisadores e os membros voluntários da comunidade envolvidos no trabalho pela equipe do NEAD.TIS.Os jovens da comunidade também receberam treinamento emduas oficinas que aconteceramno mesmo espaço e horário regular das atividades do curso de Informática.

A página do WikiIUSC < http:/ / www.wiki.fmb.unesp.br/> também foi, posteriormente, apresentada e disponibilizada para outras instituições da área de referência, como forma de ampliar a participação da comunidade nessa construção coletiva. 
A última etapa desta investigação constou da descrição e análise do processo e dos resultados alcançados, que são apresentados a seguir.

\section{RESULTADOS}

A partir do conteúdo desenvolvido pela disciplina IuscI no estudo do território bem como dos relatórios produzidos pelos alunos da graduação, conforme discutido anteriormente, a equipe de pesquisa definiu os seguintes tópicos de conteúdo para a página Wiki:1) histórico; 2) dados gerais 3) saúde; 4) educação; 5) meio ambiente; 6) cultura; 7) religiões; 8) transporte; 9) pontos de referência; 10) organizações sociais; 11) projetos sociais; e 12)links.

Uma vez construída a página Wiki (WikiIUSC), foram incluídos os conteúdos produzidos pelos alunos regulares da graduação, que estão disponíveis na plataforma Moodle da FMB-Unesp.

Após a construção da página WikiIUSC pelo NEAD.TIS, houve o treinamento dos jovens da comunidade participantes do projeto no uso dos recursos disponíveis na página Wiki, tais como: ferramentas de edição de textos; criação de link interno e externo; utilização do espaço de discussão; postagem de fotos, etc. A oficina permitiu revelar aos jovens a facilidade do uso da ferramenta, bem como a possibilidade de participação de vários autores na construção do conhecimento de forma rápida. Os alunos demonstraram grande interesse em aprender a utilizar a ferramenta. Ao final de uma hora, os alunos já eram capazes de postar textos nos diferentes tópicos da página, além de criar novos tópicos, links internos para outros tópicose links externos para outras páginas da Web, além do uso dos recursos de edição.

Ainda que, nessa etapa de desenvolvimento do projeto, não tenha sido possível a interação simultânea entre os alunos da graduação de Medicina e Enfermagem e os jovens do projeto, foi possível alcançar certa integração e/ou complementação entre as informações disponibilizadas na página Wiki (WikiIUSC), característica fundamental na construção de um ambiente colaborativo.

Junto ao grupo de adolescentes houve pouco interesse em acessar as informações presentes na página a respeito do bairro e também certo receio em editá-las. Uma das dificuldades enfrentadas foi a impossibilidade de se trabalhar com um mesmo grupo de jovens do projeto social, uma vez que as turmas do curso de Informática são organizadas de acordo com a participação dos alunos nas demais atividades do projeto. Com isso, a rotatividade dos alunos limitou as possibilidades de desenvolvimento do projeto. Apesar das dificuldades enfrentadas, optou-se por manter o trabalho com esse grupo de adolescentes, dado o vínculo já estabelecido com ele e a disponibilidade e colaboração dos coordenadores do projeto. Assim, pactuou-se que a estratégia utilizada seria a valorização do projeto social e de seus participantes, em um esforço para incluir o próprio projeto social na página WikiIUSC, dando visibilidade ao projeto e ao trabalho de sua inclusão produzido pelos jovens. Estes jovens, por sua vez, apropriaram-se da ferramenta e a utilizaram para incluir outras atividades que desenvolveram no projeto social, como um campeonato de futebol e relatos e fotos de atividades realizadas anteriormente. Com isso foi possível assegurar uma participação relevante do grupo de jovens na produção de parte da página Wiki, com elementos significativos de seu cotidiano.

Não houve, para o grupo de jovens da comunidade, dificuldades de natureza técnica quantoà apropriação e ao uso da ferramenta Wiki na construção coletiva da página WikiIUSC, o que reforça o fato desta ser uma ferramenta de manuseio simples ${ }^{12-13}$.

Confrontando os resultados obtidos com a literatura analisada, pôde-se observar que os adolescentes participantes do estudo, embora não tenham utilizado o software em toda sua potencialidade, apropriaram-se dele e ampliaram a página Wiki com informações sobre as atividades em que estão diretamente envolvidos no projeto social ${ }^{12-13}$.

Os alunos, tanto do projeto quanto do Iusc, postaram informações sobre alguns tópicos contidos no site e o fizeram, em sua maioria, de maneira linear, sem a utilização do recurso de criação de links. Em outra experiência pedagógica com o Wiki ${ }^{13}$,constatou-se que a criação de links éuma de suas ferramentas úteis, por permitir a expansão dos textos, os quais representam a riqueza dessa ferramenta em relação à conexão de conhecimentos e saberes.

Gomes observou que as intervenções iniciais foram mais formais e que, progressivamente, por um domínio maior da ferramenta, passaram a ser mais soltas e pessoais ${ }^{13}$. Neste trabalho, à medida que os participantes foram aumentando sua participação no WikiIUSC, eles foram se sentindo mais confiantes para incluir na plataforma as atividades que lhes eram significativas. Assim, colocaram informações sobre o campeonato de futebol de que participavam e de festas, como forma de divulgá-los interna e externamente ao projetosocial. Vale ressaltar a dificuldade que se teve em trabalhar com o grupo completo nos diferentes encontros realizados, devido à diversidade de atividades e mudanças frequentes de horário das atividades do curso de Informática.

Quanto aos problemas operacionais no uso da plataforma Wiki, identificou-se a dificuldade de atualização simultânea 
de páginas quando vários participantes utilizam-na concomitantemente, o que fez com que, nesse momento, apenas uma das versões inseridas fosse salva. No que se refere ao controle de acesso (quem e quando pode ver ou editar), optou-se por manter o livre acesso à edição de textos, cabendo aos pesquisadores as revisões periódicas no site.

O maior problema enfrentado foi de natureza operacional, dada a dinâmica do próprio projeto social que dá aos alunos grande flexibilidade de participação nas diversas atividades e também a pouca disponibilidade de horários para utilização da sala de Informática. Dessa maneira, tarefas que tinham sido propostas a alguns participantes não puderam ser cumpridas. Destaca-se a participação do professor de Informática, que, em função do contato mais próximo com os alunos, estimulou a edição de textos também fora do horário das oficinas, funcionando em vários momentos como facilitador e apoiador da atividade. De fato, os professores têm papel fundamental enquanto fomentadores em atividades que façam uso do Wiki, pois são eles que podem propor as atividades com certa periodicidade (Notari, 2006), como o ocorrido durante o processo realizado.

A construção coletiva inicial da página pelos diferentes olhares dos alunos e tutores envolvidos na disciplina Iusc e, posteriormente, agregada à contribuição dos participantes deste projeto (alunos, professor, pesquisadores) no que se refere ao território em questão, foi sendo gradualmente integrada, transformando-seem um único produto: a página Wiki produzida com o texto coletivo.

O estudo permitiu verificar a viabilidade e potencialidade de uso do Wiki como ferramenta de inteligência coletiva, por permitir uma troca de saberes entre alunos e comunidade, valorizando,assim, toda forma de conhecimento e a expressão das singularidades ${ }^{4-6,9}$.

\section{CONCLUSÕES}

O Programa de Incentivo às Mudanças Curriculares nos Cursos de Medicina (Promed) e o Programa Nacional de Reorientação da Formação Profissional em Saúde (Pró-Saúde) viabilizaram a criação e desenvolvimento da disciplina Iusc nesses anos. $\mathrm{O}$ uso da ferramenta Wiki veio potencializar o alcance dos objetivos do Iusc, especialmente para: identificar equipamentos sociais, redes de apoio e recursos disponíveis para promoção da saúde e qualidade de vida no território; conhecer e utilizar métodos e técnicas apropriadas para o reconhecimento da situação de vida e necessidades de saúde da comunidade (como vivem, porque adoecem e morrem os cidadãos); e a sistematizar o trabalho desenvolvido para fins de avaliação e historicidade ${ }^{1}$.
A construção e a implementação da página do WikiIUSC, como um espaço de comunicação e colaboração entre estudantes da graduação de Medicina e Enfermagem e membros da comunidade, deve estimular sua adoção como instrumento pedagógico de produção hipertextual,reduzindo os limites entre leitor e autor na disciplina Iusc e, sobretudo, espera-se que possa ajudar a promover a cooperação mútua entre Universidade e comunidade.

Por fim, é importante registrar que tanto os alunos do Iusc envolvidos com este projeto quanto os membros da comunidade reconheceram a importância do trabalho realizado e manifestaram interesse pela continuidade da proposta. A utilização do conceito de território como alicerce na construção de uma identidade coletiva para a comunidade, esta com participação efetiva de seus membros e instituições, nos moldes apresentados neste projeto, cria novas perspectivas no desenvolvimento das chamadas redes sociais.

Apoio: Projeto Financiado pelo Programa Nacional de Reorientação Profissional da Formação Profissional em Saúde -Pró-Saúde/ Ministério da Saúde e Ministério da Educação e Fundação de Amparo à Pesquisa do Estado de São Paulo -Fapesp: (Processo: 2008/07188-7).

Apoio Fundunesp (00128/10) e Capes (0766/10-0).

\section{REFERÊNCIAS}

1. Cyrino EG, ed. A universidade na comunidade: educação médica em transformação. Botucatu: Unesp; 2005.

2. Cyino EG. et al. Em busca da recomposição da arte do cuidado e do fazer/aprender: a interação universidade, serviço e comunidade na Faculdade de Medicina de Botucatu/UNESP. In: Pinheiro R, Ceccim RB, Mattos RA. (org.). Ensino-trabalho-cidadania: novas marcas ao ensinar integralidade no SUS. Rio de Janeiro: ABRASCO; 2006. p.71-84.

3. Vygotsky LS. A formação social da mente. $3^{\mathfrak{a}}$ ed. São Paulo: Martins Fontes; 1989.

4. Teixeira RR. O desempenho de um serviço de atenção primária à saúde na perspectiva da inteligência coletiva. Interface (Botucatu). 2005;9(17):219-34.

5. vy P. A Inteligência coletiva: por uma antropologia do ciberespaço. 3a ed. São Paulo: Loyola; 1994.

6. Moura AH. A psicoterapia institucional e o clube dos saberes. São Paulo: Hucitec; 2003.

7. Lévy P. As tecnologias da inteligência: o futuro do pensamento na era da informática. Rio de Janeiro: Editora 34; 1993.

8. Crino AP. Entre a ciência e a experiência: uma cartografia do autocuidado no diabetes. São Paulo:Unesp; 2009. 
9. Costa R. A cartografia dos Saberes: a sinergia das Inteligências e a partilha dos conhecimentos. [S.l:Sn]. (Biblioteca: textos básicos, DDIC): 2004.

10. Pereira MPB, Barcellos C. O território no programa de saúde da família. Hygeia. 2006;2(2):47-55.

11. Thiollent M. Metodologia da pesquisa-ação. São Paulo: Cortez; 2007.

12. Cunningham W. Content Creation Wiki. [Online]. [acesso em 1 maio 2010]. Disponível em: http:/ / c2.com/cgi/wiki .

13. Gomes MR. Wiki: uma experiência pedagógica. Rumores Revista de Comunicação, Linguagem e Mídias. 2007;1(1):118.

14. Ebersbach A, Glaser M, Heigl R. Wiki: Web collaboration. New York: Springer; 2006.

\section{CONTRIBUIÇÃO DOS AUTORES}

Antonio Pithon Cyrino e Vera Lúcia Garcia foram responsáveis pela concepção e desenho da pesquisa, orientação do trabalho de campo, análise dos dados e redação final do texto. Viviany Menossi do Amaral e Ana Cláudia Cavalcante Espósito foram responsáveis pela revisão bibliográfica, coleta e análise dos dados e elaboração dos relatórios de pesquisa. Denise de Cássia Moreira Zornoff foi responsável pela estruturação da plataforma wiki. Eliana Goldfarb Cyrino e Denise de Cássia Moreira Zornoff contribuíram na revisão crítica do manuscrito.

\section{CONFLITO DE INTERESSES}

Declarou não haver.

\section{ENDEREÇO PARA CORRESPONDÊNCIA}

Antonio Pithon Cyrino

Faculdade de Medicina de Botucatu - UNESP

Depto de Saúde Pública

Distrito de Rubião Jr. -

Cx. Postal: 549

Botucatu - SP

CEP. 18618-970

E-mail: acyrino@fmb.unesp.br 